\title{
Significant Improvement of Semiconducting Performance of the Diketopyrrolopyrrole-Quaterthiophene Conjugated Polymer through Side-Chain Engineering via Hydrogen-Bonding
}

Jingjing Yao, Chenmin Yu, Zitong Liu,* Hewei Luo, Yang Yang, Guanxin Zhang, Deqing Zhang*

Beijing National Laboratory for Molecular Sciences, Organic Solids Laboratory, Institute of Chemistry, Chinese Academy of Sciences, Beijing 100190, China

E-mail: dqzhang@iccas.ac.cn

1. Thermogravimetric Analysis (TGA) and Differential Scanning Calorimetry (DSC)

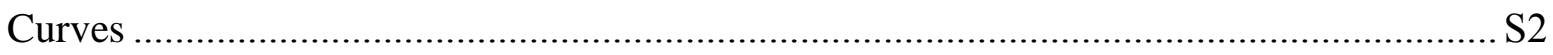

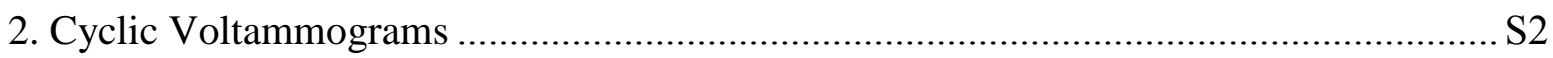

3. Synthesis and Characterization of pDPP4T, pDPP4T-A, pDPP4T-B and pDPP4T-C. S3 4. HOMO/LUMO Energies and Band Gaps of pDPP4T-A, pDPP4T-B and pDPP4T-C . S5

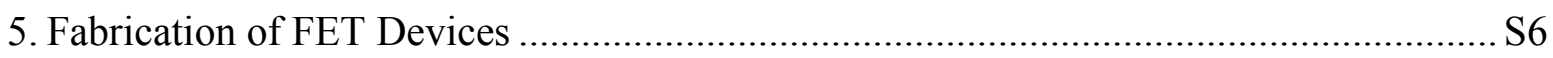

6. Transfer and Output Curves of BGBC and BGTC Devices with Thin Films of pDPP4T-1, pDPP4T-2, pDPP4T-3, pDPP4T, pDPP4T-A, pDPP4T-B and pDPP4T-C S8



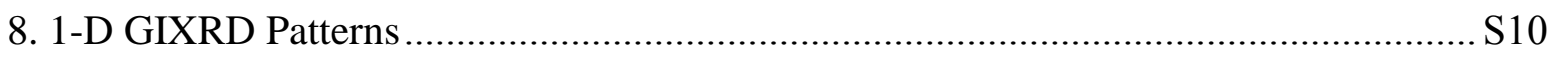

9. AFM Images of pDPP4T-A, pDPP4T-B and pDPP4T-C...................................... S12

10. Fabrication of Organic Photovoltaic Cells .............................................................. $\mathrm{S} 12$

11. $J$ - $V$ Curves and IPCE Spectra of pDPP4T-A, pDPP4T-B and pDPP4T-C with PC $_{71} \mathrm{BM}$ S13

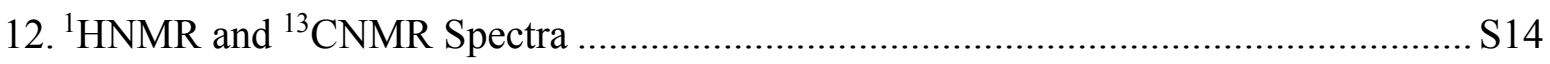


1. Thermogravimetric Analysis (TGA) and Differential Scanning Calorimetry (DSC) Curves
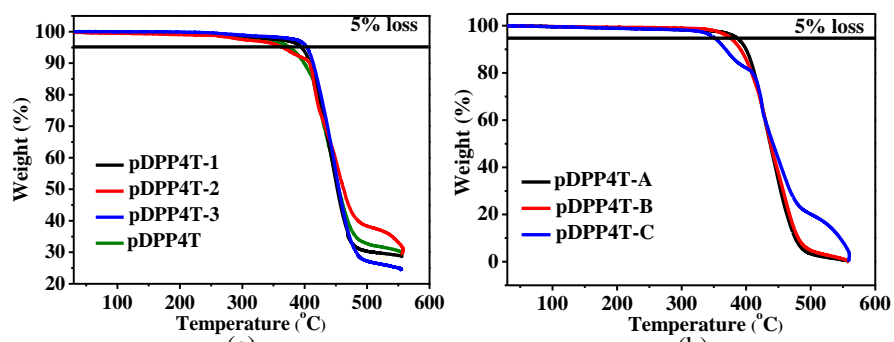

(a)
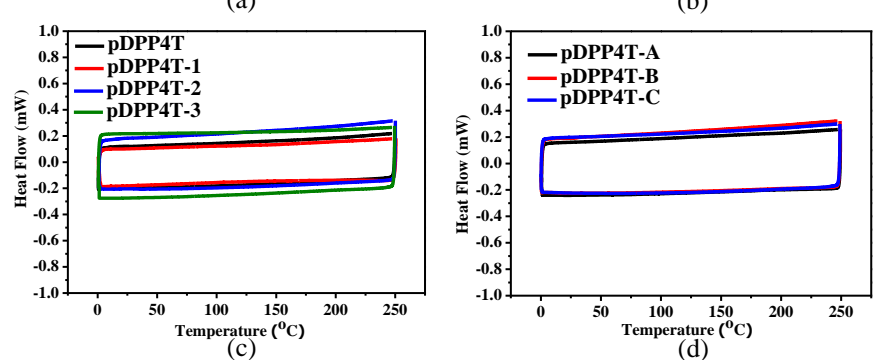

Figure S1. (a-b) TGA curves of pDPP4T-1, pDPP4T-2, pDPP4T-3, pDPP4T, pDPP4T-A, pDPP4T-B and pDPP4T-C: heating rate: $10{ }^{\circ} \mathrm{C} / \mathrm{min}$. From $25{ }^{\circ} \mathrm{C}$ to $550{ }^{\circ} \mathrm{C}$ under nitrogen atmosphere; (c-d) DSC curves (endo up) of pDPP4T-1, pDPP4T-2, pDPP4T-3, pDPP4T, pDPP4T-A, pDPP4T-B and pDPP4T-C recorded at a heating and cooling rate $\left(0-250{ }^{\circ} \mathrm{C}\right)$ of $10^{\circ} \mathrm{C} / \mathrm{min}$ under nitrogen.

\section{Cyclic Voltammograms}

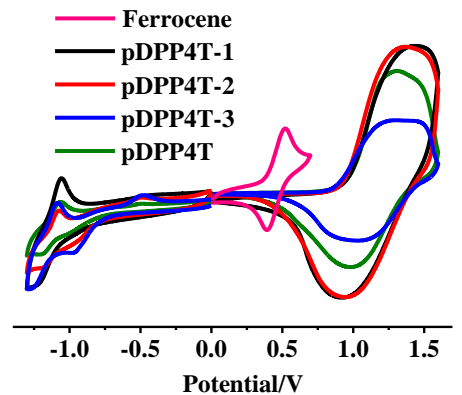

(a)

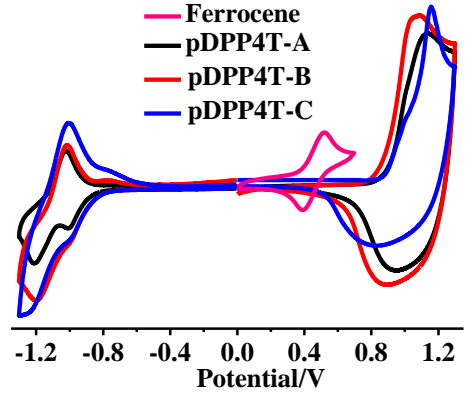

(b)

Figure S2. Cyclic voltammograms of pDPP4T-1, pDPP4T-2, pDPP4T-3, pDPP4T, pDPP4T-A, pDPP4T-B and pDPP4T-C films at a scan rate of $100 \mathrm{mVs}^{-1}$. Pt was used as working electrode and counter electrode and $\mathrm{Ag} / \mathrm{AgCl}$ (saturated $\mathrm{KCl}$ ) as reference electrode; $n$ - $\mathrm{Bu}_{4} \mathrm{NPF}_{6}(0.1 \mathrm{M})$ in $\mathrm{CH}_{3} \mathrm{CN}$ as supporting electrolyte. For calibration, the redox potential of ferrocene/ferrocenium $\left(\mathrm{Fc} / \mathrm{Fc}^{+}\right)$was measured under the same conditions. 
3. Synthesis and Characterization of pDPP4T, pDPP4T-A, pDPP4T-B and pDPP4T-C

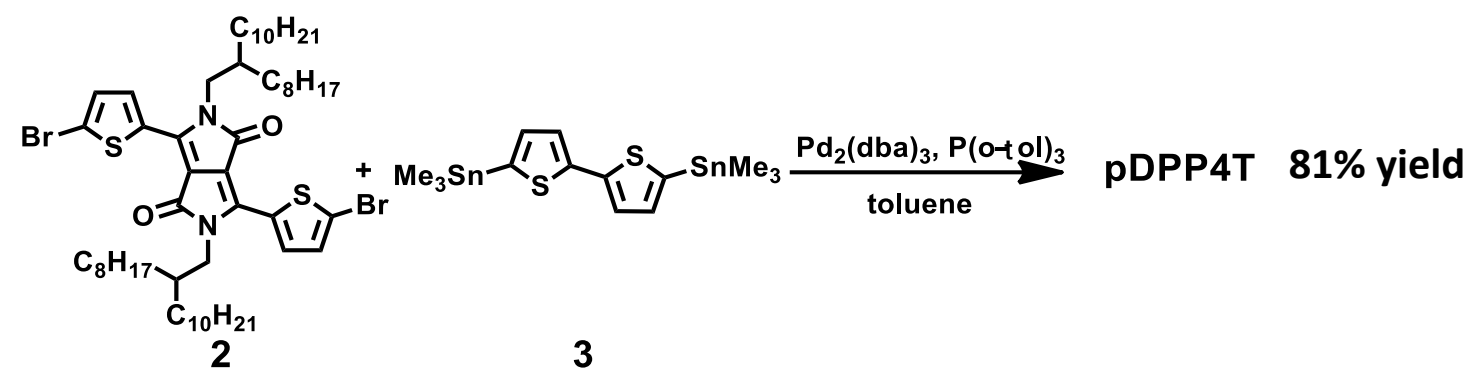

Synthesis of pDPP4T. Compound 2 (101.9 mg, $0.10 \mathrm{mmol})$, compound 3 (49.2 mg, $0.10 \mathrm{mmol}), \mathrm{P}(o \text {-tol })_{3}(4.9 \mathrm{mg}, 0.016 \mathrm{mmol})$ and $\mathrm{Pd}_{2}(\mathrm{dba})_{3}(1.8 \mathrm{mg}, 0.0020 \mathrm{mmol})$ were used. The purified polymer was collected to give deep green solid ( $83.3 \mathrm{mg}, 81 \%$ yield). ${ }^{1} \mathrm{H}$ NMR $\left(500 \mathrm{MHz}, 1,1,2,2\right.$-tetrachloroethane- $\left.d_{2}, 100{ }^{\circ} \mathrm{C}\right): \delta 8.98-8.92(\mathrm{~m}, \mathrm{br}, 2 \mathrm{H}), 7.31-6.94(\mathrm{~m}, \mathrm{br}$, $6 \mathrm{H}), 4.09-4.02(\mathrm{~m}, \mathrm{br}, 4 \mathrm{H}), 2.18-2.03(\mathrm{~m}, \mathrm{br}, 10 \mathrm{H}), 1.30(\mathrm{~s}, 56 \mathrm{H}), 0.92(\mathrm{~s}, 12 \mathrm{H}) ;{ }^{13} \mathrm{C} \mathrm{NMR}$ (100 MHz, solid): $\delta 160.09,140.33,136.05,128.04,123.69,107.94,45.24,38.36,32.08$, $30.09,23.05,14.41 ; M_{\mathrm{w}} / M_{\mathrm{n}}(\mathrm{GPC})=40.2 / 18.8 \mathrm{~kg} \mathrm{~mol}^{-1}$. Anal. calcd for $\left(\mathrm{C}_{62} \mathrm{H}_{90} \mathrm{~N}_{2} \mathrm{O}_{2} \mathrm{~S}_{4}\right)_{\mathrm{n}}: \mathrm{C}$, 72.75; H, 8.86; N, 2.74; S, 12.53. Found: C, 72.50; H, 8.92; N, 2.78; S, 12.39 .



Synthesis of pDPP4T-A. Compound 6 (2.6 mg, $0.0033 \mathrm{mmol})$, compound 2 (101.9 mg, $0.10 \mathrm{mmol})$, compound $3(50.7 \mathrm{mg}, 0.10 \mathrm{mmol}), \mathrm{P}(o-\mathrm{tol})_{3}(5.0 \mathrm{mg}, 0.016 \mathrm{mmol})$ and $\mathrm{Pd}_{2}(\mathrm{dba})_{3}(1.9 \mathrm{mg}, 0.0021 \mathrm{mmol})$ were used. The purified polymer was collected to give deep green solid (86.7 mg, 82\% yield). ${ }^{1} \mathrm{H}$ NMR (500 MHz, 1,1,2,2-tetrachloroethane- $d_{2}$, $\left.100{ }^{\circ} \mathrm{C}\right): \delta 8.85(\mathrm{~s}, \mathrm{br}, 2 \mathrm{H}), 7.07-6.91(\mathrm{~m}, \mathrm{br}, 6 \mathrm{H}), 4.09$ (s, br, 4H), 2.25-2.08 (m, br, 10H), 
1.67-1.32 (m, br, 56H), 0.93 (s, 12H); ${ }^{13} \mathrm{C}$ NMR (100 MHz, solid): $\delta 160.91,140.94,137.32$, $129.00,124.76,108.64,45.08,38.79,37.63,32.66,30.58,23.56,14.88 . M_{\mathrm{w}} / M_{\mathrm{n}}(\mathrm{GPC})=$ 211.6/74.0 kg mol ${ }^{-1}$. Anal. calcd. for $\left(\mathrm{C}_{1936} \mathrm{H}_{2878} \mathrm{~N}_{62} \mathrm{O}_{62} \mathrm{~S}_{124}\right)_{\mathrm{n}}$ : C, 72.69; H, 9.07; N, 2.71; $\mathrm{S}$, 12.43. Found: C, 72.27; H, 8.57; N, 2.82; S, 12.51.

Synthesis of pDPP4T-B. Compound 6 (4.0 mg, $0.0050 \mathrm{mmol})$, compound 2 (101.9 mg, $0.10 \mathrm{mmol})$, compound $3(51.8 \mathrm{mg}, 0.11 \mathrm{mmol}), \mathrm{P}(o-\mathrm{tol})_{3}(5.1 \mathrm{mg}, 0.017 \mathrm{mmol})$ and $\mathrm{Pd}_{2}(\mathrm{dba})_{3}(1.9 \mathrm{mg}, 0.0021 \mathrm{mmol})$ were used. The purified polymer was collected to give deep green solid (88.7 mg, 83\% yield). ${ }^{1} \mathrm{H}$ NMR (500 MHz, 1,1,2,2-tetrachloroethane- $d_{2}$, $\left.100{ }^{\circ} \mathrm{C}\right): \delta 8.89(\mathrm{~s}, \mathrm{br}, 2 \mathrm{H}), 7.08-6.93(\mathrm{~m}, \mathrm{br}, 6 \mathrm{H}), 4.09$ (s, br, 4H), 2.25-2.07 (m, br, 10H), 1.69-1.32 (m, br, 56H), 0.93 (s, 12H); ${ }^{13} \mathrm{C}$ NMR (100 MHz, solid): $\delta 160.87,141.25,136.74$, $128.59,124.29,108.37,45.46,38.73,32.67,30.72,23.62,14.94 . M_{\mathrm{w}} / M_{\mathrm{n}}(\mathrm{GPC})=$ 190.9/91.5 kg mol${ }^{-1}$. Anal. calcd. for $\left(\mathrm{C}_{1306} \mathrm{H}_{1938} \mathrm{~N}_{42} \mathrm{O}_{42} \mathrm{~S}_{84}\right)_{\mathrm{n}}: \mathrm{C}, 72.64 ; \mathrm{H}, 9.05 ; \mathrm{N}, 2.72 ; \mathrm{S}$, 12.47. Found: C, 71.89; H, 8.68; N, 2.80; S, 12.49 .

Synthesis of pDPP4T-C. Compound 6 (8.0 mg, $0.010 \mathrm{mmol}$ ), compound 2 (101.9 mg, $0.10 \mathrm{mmol})$, compound $3(54.1 \mathrm{mg}, 0.11 \mathrm{mmol}), \mathrm{P}(o-\text { tol })_{3}(5.4 \mathrm{mg}, 0.018 \mathrm{mmol})$ and $\mathrm{Pd}_{2}(\mathrm{dba})_{3}(2.0 \mathrm{mg}, 0.0022 \mathrm{mmol})$ were used. The purified polymer was collected to give deep green solid (92.2 mg, 82\% yield). ${ }^{1} \mathrm{H}$ NMR (500 MHz, 1,1,2,2-tetrachloroethane- $d_{2}$, $\left.100{ }^{\circ} \mathrm{C}\right): \delta 8.99-8.90(\mathrm{~m}, \mathrm{br}, 2 \mathrm{H}), 7.14-6.97(\mathrm{~m}, \mathrm{br}, 6 \mathrm{H}), 4.11-4.00(\mathrm{~s}, \mathrm{br}, 4 \mathrm{H}), 2.10-2.06(\mathrm{~m}$, br, 10H), 1.47-1.33 (m, br, 56H), 0.92 (s, 12H); ${ }^{13} \mathrm{C}$ NMR (100 MHz, solid): $\delta$ 160.21, $140.49,136.35,128.20,123.69,108.09,45.09,38.55,31.93,30.14,23.05,14.39 . M_{\mathrm{w}} / M_{\mathrm{n}}$ 
$(\mathrm{GPC})=207.8 / 94.6 \mathrm{~kg} \mathrm{~mol}^{-1}$. Anal. calcd. for $\left(\mathrm{C}_{666} \mathrm{H}_{958} \mathrm{~N}_{22} \mathrm{O}_{22} \mathrm{~S}_{44}\right)_{\mathrm{n}}: \mathrm{C}, 72.48 ; \mathrm{H}, 8.75 ; \mathrm{N}$, 2.79; S, 12.78. Found: C, 72.46; H, 8.75; N, 2.50; S, 12.88 .

4. HOMO/LUMO Energies and Band Gaps of pDPP4T-A, pDPP4T-B and pDPP4T-C Table S1. Absorption, Onset Redox Potentials, HOMO/LUMO Energies and Band Gaps of pDPP4T-A, pDPP4T-B and pDPP4T-C.

\begin{tabular}{|c|c|c|c|c|c|c|c|c|}
\hline \multirow[t]{2}{*}{ polymer } & \multicolumn{2}{|c|}{$\begin{array}{c}\lambda_{\max }{ }^{\mathrm{a}}(\mathrm{nm}) \\
\left(\varepsilon_{\max }, \mathrm{M}^{-1} \mathrm{~cm}^{-1}\right)^{\mathrm{b}} \\
\end{array}$} & \multirow{2}{*}{$\begin{array}{c}E_{\text {redl }}{ }^{\text {onset }} \\
(\mathrm{V})^{c}\end{array}$} & \multirow{2}{*}{$\begin{array}{c}E_{\mathrm{LUMO}} \\
(\mathrm{eV})^{d}\end{array}$} & \multirow{2}{*}{$\begin{array}{c}E_{\text {oxl }}^{\text {onset }} \\
(\mathrm{V})^{c}\end{array}$} & \multirow{2}{*}{$\begin{array}{c}E_{\text {HOMO }} \\
(\mathrm{eV})^{d}\end{array}$} & \multirow{2}{*}{$\begin{array}{l}E_{\mathrm{g}}{ }^{\mathrm{cv}} \\
(\mathrm{eV})^{e}\end{array}$} & \multirow{2}{*}{$\begin{array}{l}E_{\mathrm{g}}{ }^{\mathrm{opt}} \\
(\mathrm{eV})^{\dagger}\end{array}$} \\
\hline & solution & film & & & & & & \\
\hline pDPP4T-A & $784(80000)$ & 726,784 & -1.28 & -3.52 & 0.47 & -5.27 & 1.75 & 1.33 \\
\hline pDPP4T-B & $788(82000)$ & 726,790 & -1.26 & -3.54 & 0.46 & -5.26 & 1.71 & 1.32 \\
\hline pDPP4T-C & $800(83000)$ & 726,790 & -1.26 & -3.54 & 0.46 & -5.26 & 1.72 & 1.32 \\
\hline
\end{tabular}

${ }^{a}$ Absorption maxima in $\mathrm{CHCl}_{3}$ solution $\left(1.0 \times 10^{-5} \mathrm{M}\right.$ for each polymer) and the spin-coated thin film; ${ }^{b}$ Molar extinction coefficient $\left(\varepsilon_{\max }, \mathrm{M}^{-1} \mathrm{~cm}^{-1}\right) ;{ }^{c}$ Onset potentials $\left(\mathrm{V}\right.$ vs $\left.\mathrm{Fc} / \mathrm{Fc}^{+}\right)$for reduction $\left(E_{\text {redl }}{ }^{\text {onset }}\right)$ and oxidation $\left(E_{\text {oxl }}{ }^{\text {onset }}\right) ;{ }^{d}$ Estimated with the following equation: $E_{\mathrm{HOMO}}=-\left(E_{\text {oxl }}{ }^{\text {onset }}+4.8\right) \mathrm{eV}, E_{\mathrm{LUMO}}=-\left(E_{\text {redl }}{ }^{\text {onset }}+4.8\right) \mathrm{eV} ;{ }^{e}$ Based on redox potentials $;{ }^{f}$ Based on the absorption spectral data.
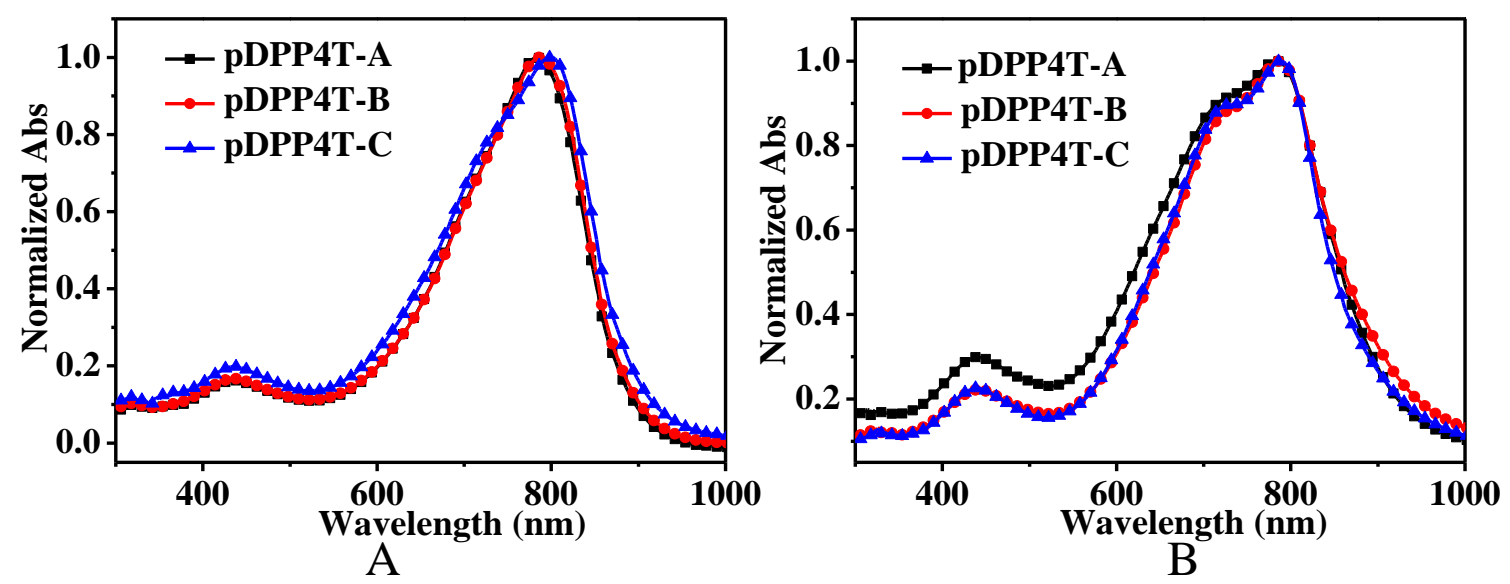

Figure S3. Normalized UV-vis absorption spectra of pDPP4T-A, pDPP4T-B and pDPP4T-C in $\mathrm{CHCl}_{3}\left(1.0 \times 10^{-5} \mathrm{M}\right)(\mathrm{A})$ and their thin films (B). 


\section{Fabrication of FET Devices}

Solutions of conjugated polymers were prepared by dissolving the copolymers in chloroform at a concentration of $7.0 \mathrm{mg} / \mathrm{mL}$ except pDPP4T-C $(3.0 \mathrm{mg} / \mathrm{mL}$ in 1,1,2,2-tetrachloroethane). The typical polymer film thickness (around 40-45 nm) was measured on profilometer (Ambios Tech. XP-2). Bottom-Gate/Bottom-Contact FETs were fabricated. A heavily doped $n$-type $\mathrm{Si}$ wafer and a layer of dry oxidized $\mathrm{SiO}_{2}(300 \mathrm{~nm}$, with roughness lower than $0.1 \mathrm{~nm}$ and capacitance of $11 \mathrm{nF} \mathrm{cm}^{-2}$ ) were used as a gate electrode and gate dielectric layer, respectively. The drain-source $(D-S)$ gold contacts $(28 \mathrm{~nm})$ were fabricated by photo-lithography. The substrates were first cleaned by sonication in acetone and water for $5.0 \mathrm{~min}$ and immersed in Piranha solution (2:1 mixture of sulfuric acid and $30 \%$ hydrogen peroxide) for $20 \mathrm{~min}$. This was followed by rinsing with deionized water and isopropyl alcohol for several times, and it was blow-dried with nitrogen. Then, the surface was modified with $n$-octadecyltrichlorosilane (OTS). After that, the substrates were cleaned in $n$-hexane, $\mathrm{CHCl}_{3}$ and isopropyl alcohol. The films of conjugated polymers were fabricated by spin-coating their solutions at $3000 \mathrm{rpm}$. The annealing process was carried out in vacuum for $1.0 \mathrm{~h}$ at each temperature.

The bottom-gate/top-contact devices with fabricated similarly except Au source/drain electrodes $(50 \mathrm{~nm})$ were deposited via thermal vacuum evaporation through a shadow mask after spin coating the semiconductor solution and then annealed at different temperatures in vacuum for $1.0 \mathrm{~h}$. Field-effect characteristics of the devices were determined in nitrogen using a Keithley 4200 SCS semiconductor parameter analyzer. 
Linear mobility was calculated according to the equation below:

$$
I_{\mathrm{DS}}=(W / L) C_{\mathrm{i}} \mu\left(V_{\mathrm{GS}}-V_{\mathrm{Th}}\right) V_{\mathrm{DS}} \quad V_{\mathrm{DS}} \ll<V_{\mathrm{GS}}-V_{\mathrm{Th}}
$$

The mobility of the OFETs in the saturation region was extracted from the following equation:

$$
I_{D S}=\frac{\mathrm{W}}{2 L} \mu C_{i}\left(V_{G S^{-}} V_{T h}\right)^{2}
$$

Where $I_{\mathrm{DS}}$ is the drain electrode collected current; $L$ and $W$ are the channel length and width, respectively; $\mu$ is the mobility of the device; $C_{\mathrm{i}}$ is the capacitance per unit area of the gate dielectric layer; $V_{\mathrm{GS}}$ is the gate voltage, and $V_{\mathrm{Th}}$ is the threshold voltage. The $V_{\mathrm{Th}}$ of the device was determined by extrapolating the $\left(I_{\mathrm{DS}, \mathrm{sat}}\right)^{1 / 2} \mathrm{vs} . V_{\mathrm{GS}}$ plot to $I_{\mathrm{DS}}=0$.

The contact resistance was determined in the following way (a. Luan, S.; Neudeck, G. W. J. Appl. Phys. 1992, 72, 766; b. Lefenfeld, M.; Blanchet, G.; Rogers, J. A. Adv. Mater. 2003, 15 , 1188.). For a BGBC FET, the $\mathrm{ON}$ resistance, $R_{\mathrm{ON}}$, in the linear operation regime (source-drain voltage << gate voltage), can be expressed as follows:

$$
R_{\mathrm{on}}=\frac{\partial V_{\mathrm{DS}}}{\partial I_{\mathrm{DS}}} \int_{V_{\mathrm{DS}} \rightarrow 0}^{V_{\mathrm{GS}}}=R_{c h}+R_{p}=\frac{L}{W \mu_{i} C_{i}\left(V_{G S}-\mathrm{V}_{\mathrm{T} h}\right)}+R_{p}
$$

where $R_{\mathrm{ch}}$ is the channel resistance, $R_{\mathrm{p}}$ is the parasitic resistance, and $V_{\mathrm{GS}}$ is the gate voltage. The parasitic resistance, $R_{\mathrm{p}}$, which is associated with the contacts between $S-D$ electrode and semiconductor layer, can be extracted by measuring the $\mathrm{ON}$ resistance, $R_{\mathrm{ON}}$, from the linear region of the FET output characteristics. We got a plot of $R_{\mathrm{ON}}$ as a function of $L$ at the gate voltage of $-30 \mathrm{~V}$, and found that the relationship of $R_{\mathrm{ON}} \mathrm{vs} L$ gives straight lines, indicating that the $\mathrm{ON}$ resistance is well expressed by Eq. (3). By extrapolating the relationship of $R_{\mathrm{ON}}$ vs $L$ to $L=0$, the contact resistance values can be determined. The 
contact resistances for BGBC devices with thin films of pDPP4T-1, pDPP4T-2, pDPP4T-3, pDPP4T, pDPP4T-A, pDPP4T-B and pDPP4T-C were determined to be $0.82 \mathrm{M} \Omega, 0.21 \mathrm{M} \Omega, 0.11 \mathrm{M} \Omega, 1.40 \mathrm{M} \Omega, 0.71 \mathrm{M} \Omega, 0.53 \mathrm{M} \Omega$ and $0.52 \mathrm{M} \Omega$, respectively.

6. Transfer and Output Curves of BGBC and BGTC Devices with Thin Films of pDPP4T-1, pDPP4T-2, pDPP4T-3, pDPP4T, pDPP4T-A, pDPP4T-B and pDPP4T-C

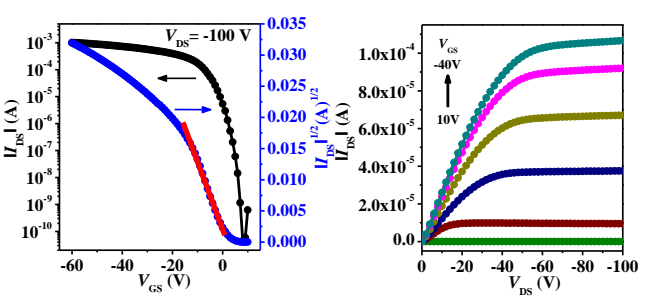

(A)

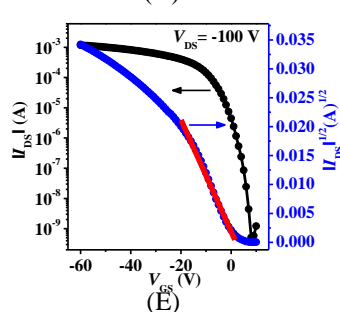

$(\mathrm{E})$

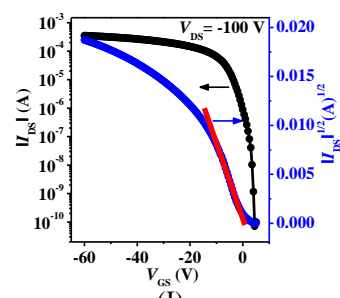

(I)

(B)

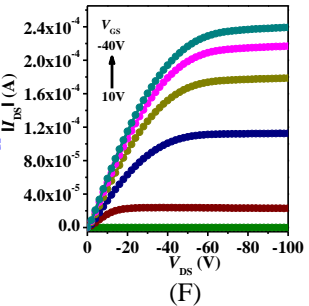

(F)

$(\mathrm{J})$
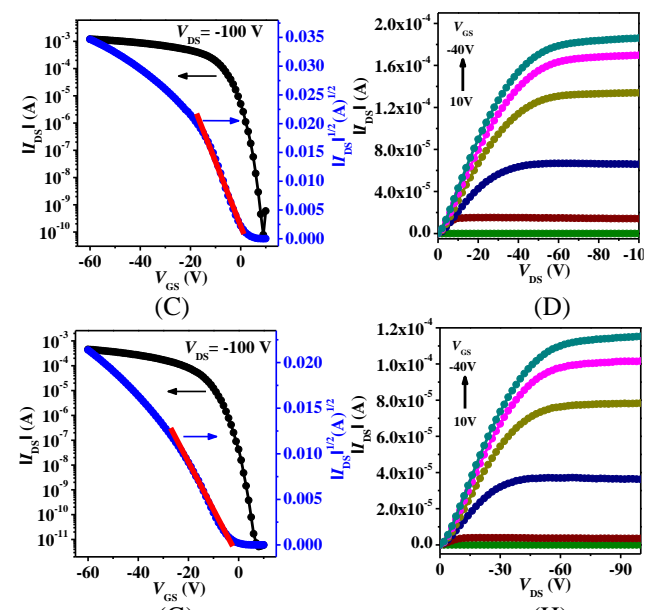

(G)



(H)
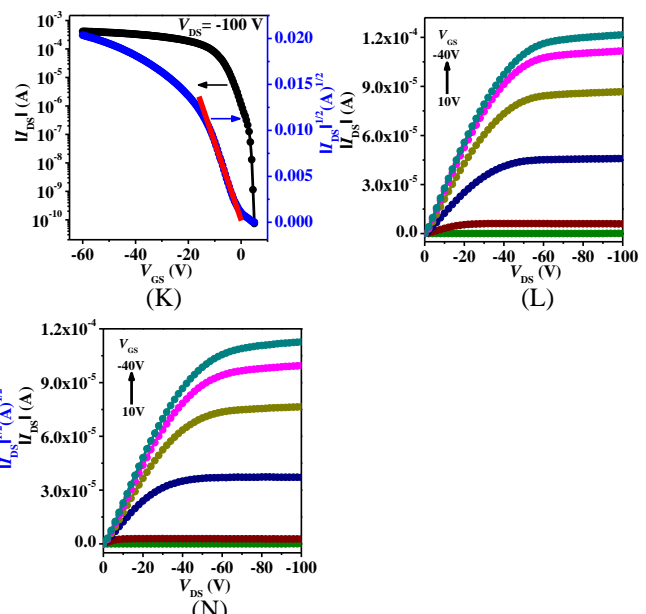

(L)

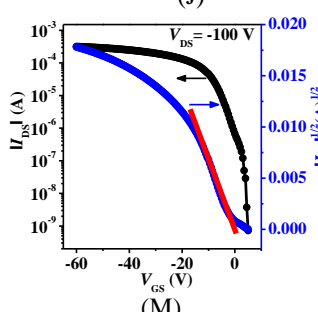

(M)
$(\mathrm{N})$

Figure S4. The transfer and output curves of BGBC FETs with thin films of pDPP4T-1 (A, B), pDPP4T-2 (C, D), pDPP4T-3 (E, F), pDPP4T (G, H), pDPP4T-A (I, J), pDPP4T-B $(\mathrm{K}, \mathrm{L})$ and $\mathbf{p D P P 4 T}-\mathrm{C}(\mathrm{M}, \mathrm{N})$ after thermal annealing at $100{ }^{\circ} \mathrm{C}$; the channel width $(W)$ and length $(L)$ were $1440 \mu \mathrm{m}$ and $50 \mu \mathrm{m}$, respectively. 



(E)

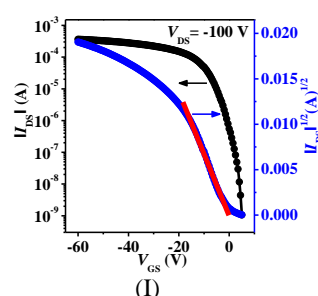

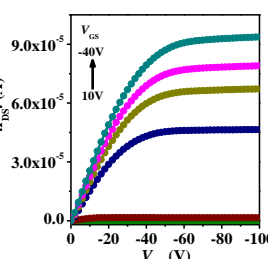

(B)

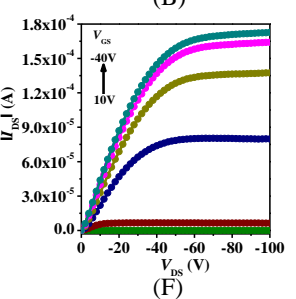

(F)
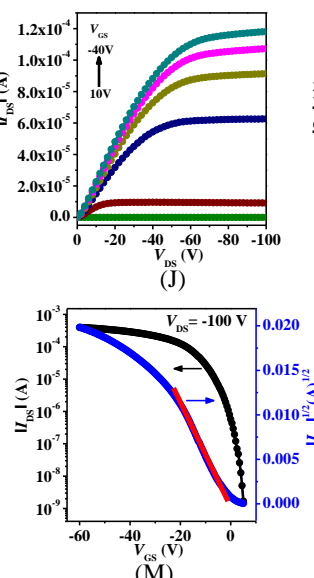

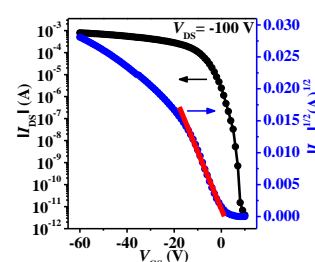

(C)


(K)

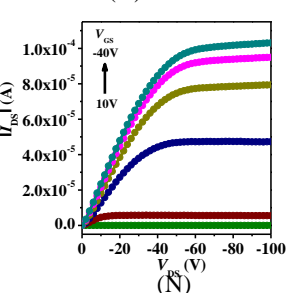



(D)
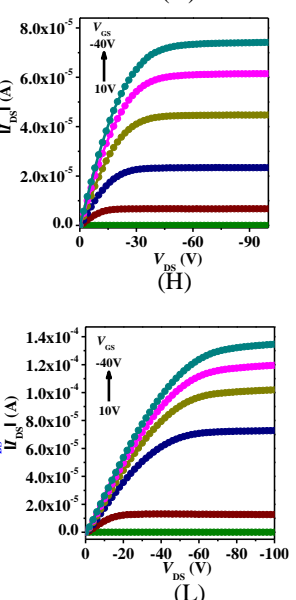

(L)

Figure S5. The transfer and output curves of BGTC FETs with thin films of pDPP4T-1 (A, B), pDPP4T-2 (C, D), pDPP4T-3 (E, F), pDPP4T (G, H), pDPP4T-A (I, J), pDPP4T-B $(\mathrm{K}, \mathrm{L})$ and pDPP4T-C $(\mathrm{M}, \mathrm{N})$ after thermal annealing at $100{ }^{\circ} \mathrm{C}$; the channel width $(W)$ and length $(L)$ were $3000 \mu \mathrm{m}$ and $100 \mu \mathrm{m}$, respectively.

Table S2. Hole Mobilities $(\mu \mathrm{h})$, Threshold Voltages $\left(V_{\mathrm{Th}}\right)$ and $I_{\mathrm{on}} / I_{\text {off }}$ Ratios for BGTC FETs with thin films of pDPP4T-1, pDPP4T-2, pDPP4T-3, pDPP4T, pDPP4T-A, pDPP4T-B and pDPP4T-C after Annealing at $100{ }^{\circ} \mathrm{C}$.

\begin{tabular}{cccc}
\hline polymer & $\mu_{\mathrm{h}}{ }^{a} / \mathrm{cm}^{2} \mathrm{~V}^{-1} \mathrm{~s}^{-1}$ & $V_{\mathrm{Th}, \mathrm{h}} / \mathrm{V}$ & $I_{\mathrm{on}} / I_{\mathrm{off}}$ \\
pDPP4T-1 & $4.8 / 4.4$ & $-3-10$ & $10^{6}-10^{7}$ \\
pDPP4T-2 & $6.4 / 5.9$ & $0-9$ & $10^{7}-10^{8}$ \\
pDPP4T-3 & $8.8 / 7.1$ & $-5-10$ & $10^{6}-10^{7}$ \\
pDPP4T-A & $3.7 / 3.1$ & $-5-8$ & $10^{5}-10^{6}$ \\
pDPP4T-B & $4.1 / 3.5$ & $-4-9$ & $10^{5}-10^{6}$ \\
pDPP4T-C & $2.6 / 2.1$ & $-3-10$ & $10^{5}-10^{6}$ \\
pDPP4T & $2.6 / 2.2$ & $-5-11$ & $10^{7}-10^{8}$ \\
\hline
\end{tabular}

a The mobilities were provided in "highest/average" form, and the performance data were obtained based on more than 10 different FETs. 


\section{Devices Stability Data}

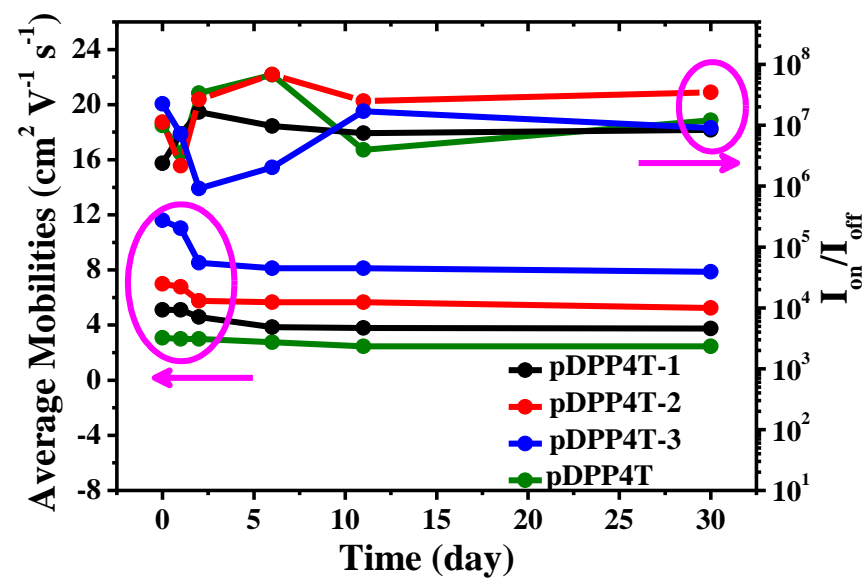

Figure S6. Variation of hole mobilities and $I_{\mathrm{on}} / I_{\mathrm{off}}$ ratios for BGBC FETs of pDPP4T-1, pDPP4T-2, pDPP4T-3 and pDPP4T after being left in air for 30 days.

\section{1-D GIXRD Patterns}

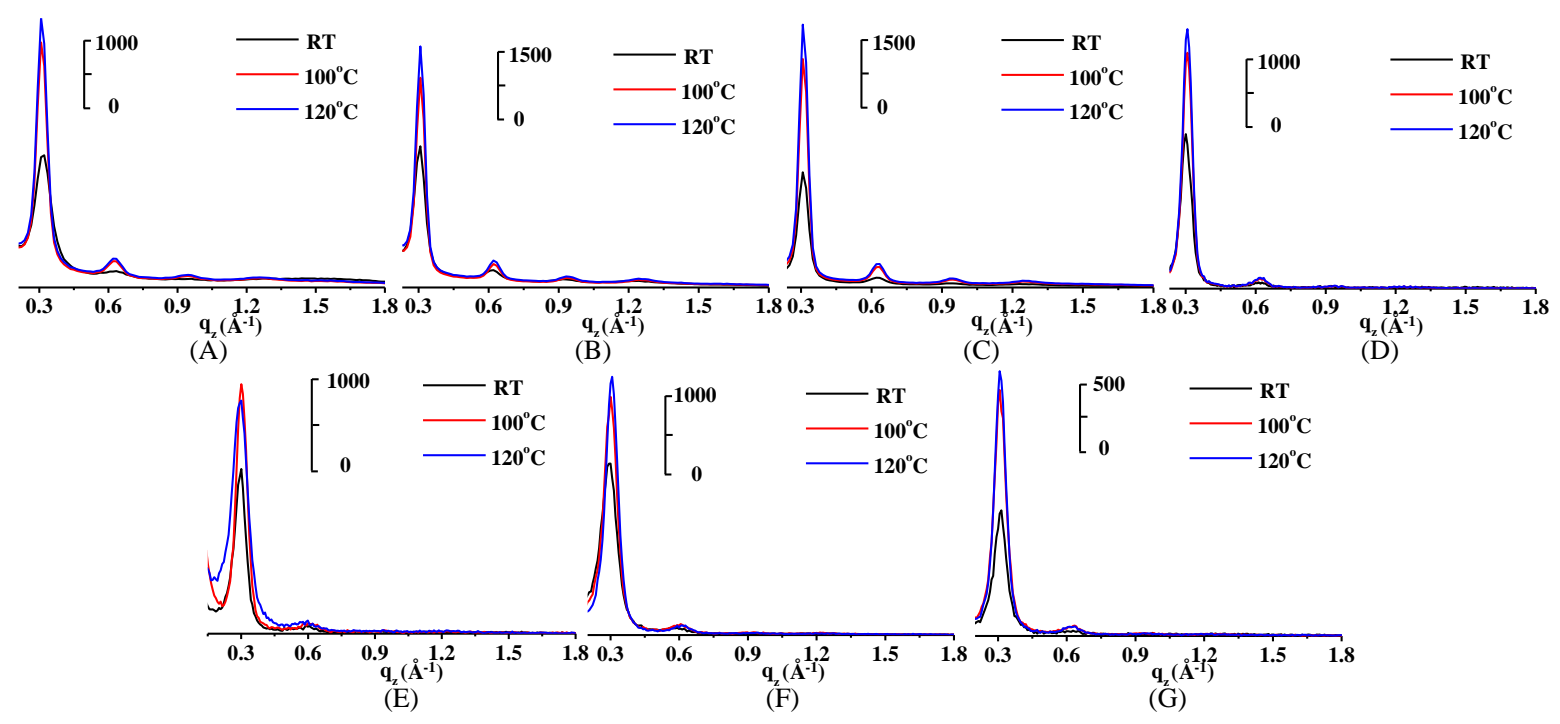

Figure S7. 1-D GIXRD patterns in the out-of-plane direction for pDPP4T-1 (A), pDPP4T-2 (B), pDPP4T-3 (C), pDPP4T (D) and pDPP4T-A (E), pDPP4T-B (F) and pDPP4T-C $(\mathrm{G})$ deposited on OTS-modified $\mathrm{SiO}_{2} / \mathrm{Si}$ substrates after thermal annealing at different temperatures. 


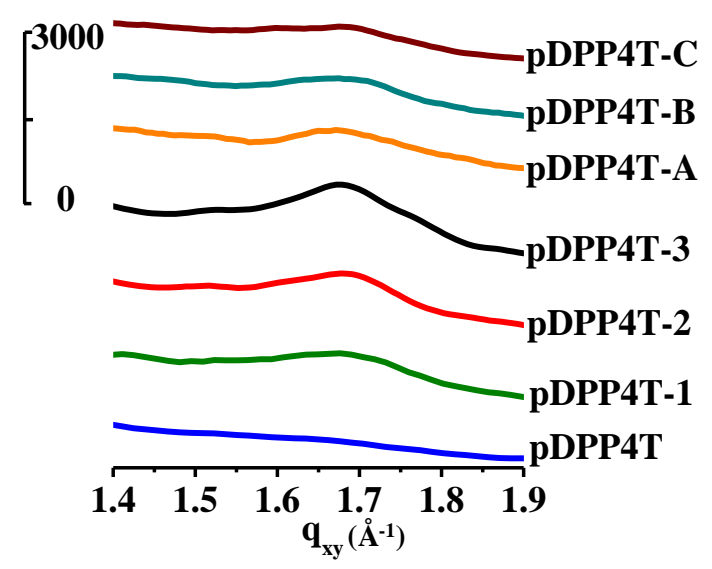

Figure S8. 1-D GIXRD patterns in the in-plane direction for pDPP4T-1, pDPP4T-2, pDPP4T-3, pDPP4T, pDPP4T-A, pDPP4T-B, and pDPP4T-C deposited on OTS-modified $\mathrm{SiO}_{2} / \mathrm{Si}$ substrates after thermal annealing at $100{ }^{\circ} \mathrm{C}$.

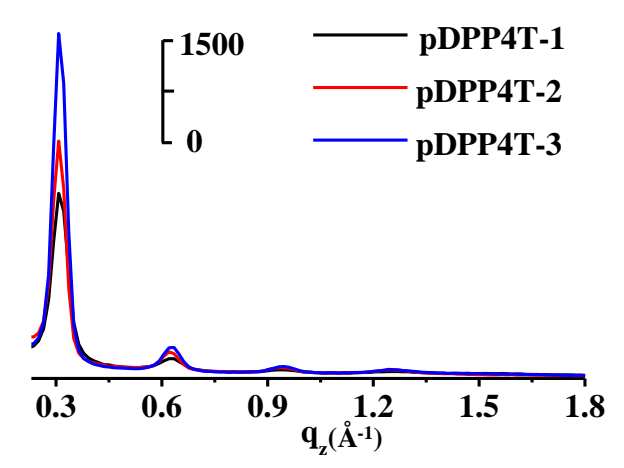

Figure S9. 1-D out-of-plane X-ray diffraction patterns of pDPP4T-1, pDPP4T-2 and pDPP4T-3 after thermal annealing at $100^{\circ} \mathrm{C}$.



Figure S10. 1-D out-of-plane X-ray diffraction patterns of pDPP4T-1 and pDPP4T-A (A), pDPP4T-2 and pDPP4T-B (B) and pDPP4T-3 and pDPP4T-C (C) after thermal annealing at $100{ }^{\circ} \mathrm{C}$. 


\section{AFM Images of pDPP4T-A, pDPP4T-B and pDPP4T-C}



Figure S11. AFM height images of thin films of pDPP4T-A (A, D, G), pDPP4T-B (B, E, H) and pDPP4T-C (C, F, I) deposited on OTS-modified $\mathrm{SiO}_{2} / \mathrm{Si}$ substrates at room temperature (up) and after thermal annealing at $100{ }^{\circ} \mathrm{C}$ (middle) and $120{ }^{\circ} \mathrm{C}$ (down).

\section{Fabrication of Organic Photovoltaic Cells}

OPVs were fabricated with ITO as the positive electrode and $\mathrm{Al}$ as the negative electrode. The patterned indium tin oxide (ITO) glass ( in an ultrasonic bath in detergent, deionized water, acetone and isopropyl alcohol, then treated in an ultraviolet-ozone chamber (Jelight Company, USA) for $30 \mathrm{~min}$. A thin layer (30 nm) of poly(3,4-ethylenedioxythi-ophene):poly(styrenesulfonate) (PEDOT:PSS, Baytron PVP AI 4083, Germany) was spin-coated onto the ITO glass and baked at $150{ }^{\circ} \mathrm{C}$ for $15 \mathrm{~min}$. Blend solution were prepared in different solvents at a total concentration of 15-18 $\mathrm{mg} / \mathrm{ml}$ (donor/acceptor weight ratio:1/2 or 1/1) and stirred 2 hours for complete dissolution. Then, the pDPP4T, pDPP4T-1, pDPP4T-2, pDPP4T-3, pDPP4T-A, pDPP4T-B and pDPP4T-C/PC 71 BM blend solution was spin-coated. The thickness (ca. 
100-120 nm) of the active layer was measured using an Ambios Technology XP-2 profilometer. Ca (ca. $20 \mathrm{~nm}$ ) and aluminum layer (ca. $70 \mathrm{~nm}$ ) were then evaporated onto the surface of the active layer under vacuum (ca. $10^{-5} \mathrm{~Pa}$ ) to form the negative electrode respectively. The active area of the device was $5.0 \mathrm{~mm}^{2}$. The $J-V$ curves were measured with a computer-controlled Keithley 236 Source Measure Unit. A xenon lamp coupled with AM 1.5 solar spectrum filters was used as the light source, and the optical power at the sample was $100 \mathrm{~mW} \mathrm{~cm}$. The incident photon to converted current efficiency (IPCE) spectra were performed at Solar Cell Spectral Response Measurement System QE-R3011 (EnliTechnololy Co. Ltd).

\section{1. $J-V$ Curves and IPCE Spectra of pDPP4T-A, pDPP4T-B and pDPP4T-C with} PC71BM
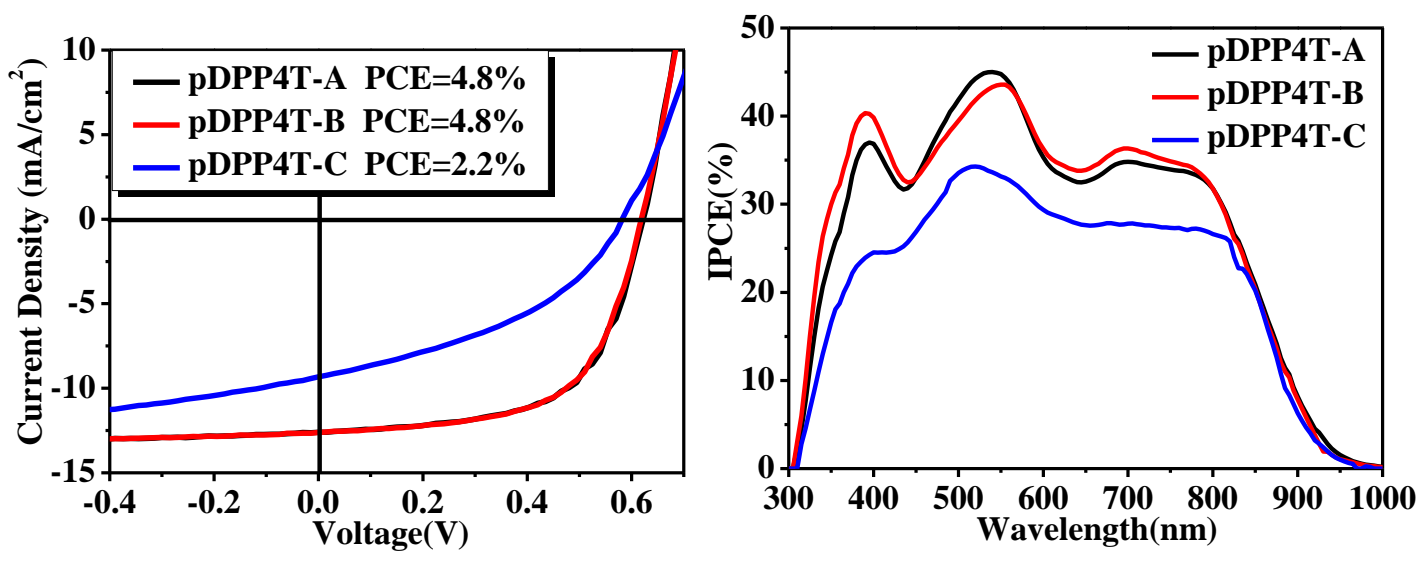

Figure S12. $J-V$ curves (left) and IPCE spectra (right) of photovoltaic cells with the respective blend films of pDPP4T-A, pDPP4T-B and pDPP4T-C with PC ${ }_{71} \mathrm{BM}$ at 1:2 weight ratio under AM 1.5 illumination $\left(100 \mathrm{~mW} / \mathrm{cm}^{2}\right)$. 


\section{2. ${ }^{1}$ HNMR and ${ }^{13}$ CNMR Spectra}

Compound 5
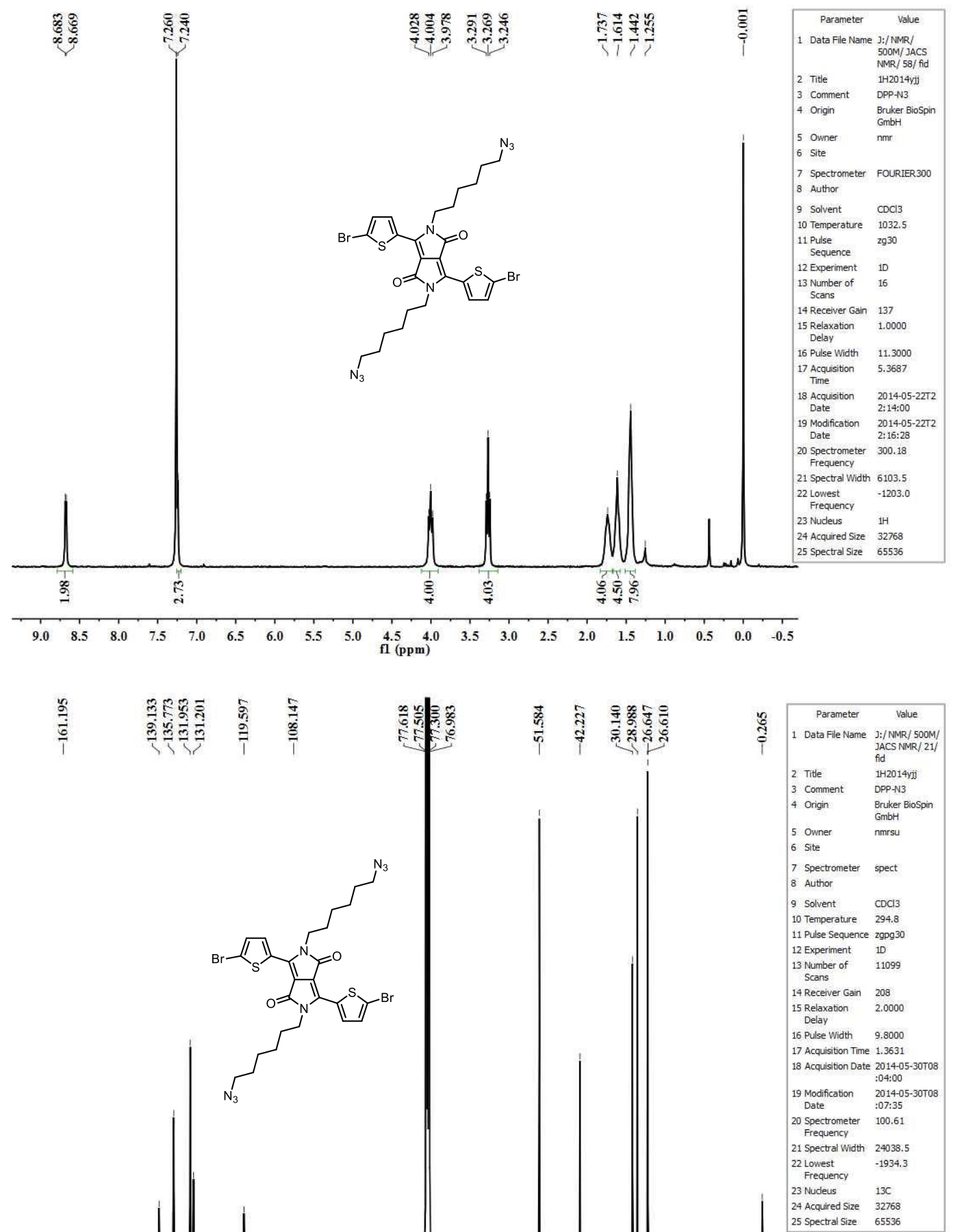

$\begin{array}{llllllllllllllllll}170 & 160 & 150 & 140 & 130 & 120 & 110 & 100 & 90 & \begin{array}{c}80 \\ \mathrm{fl}(\mathrm{ppm})\end{array} & 70 & 60 & 50 & 40 & 30 & 20 & 10 & 0\end{array}$ 


\section{Compound 1}
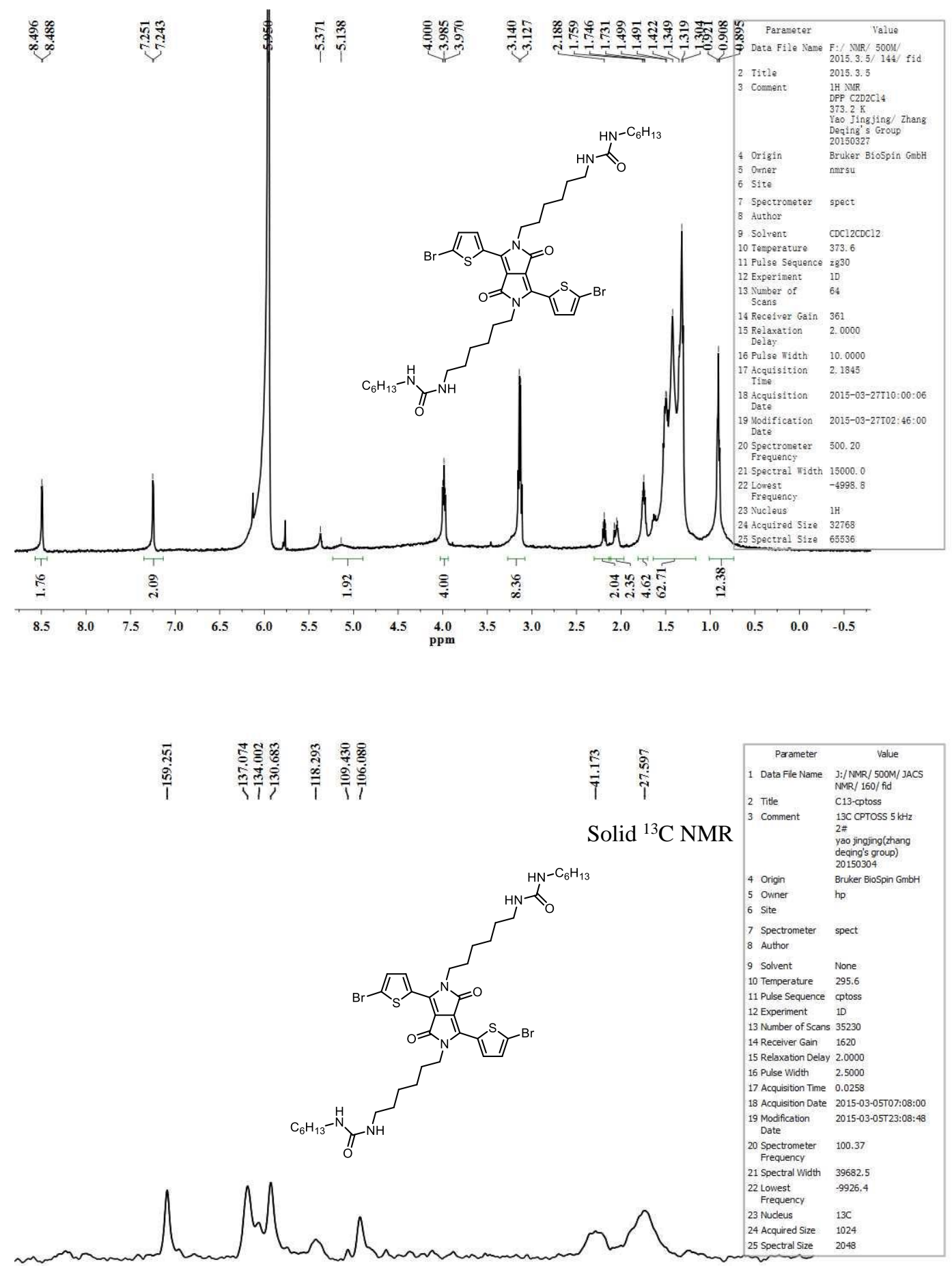

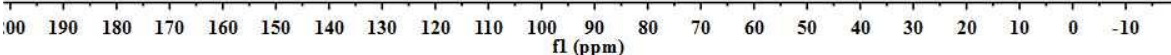


pDPP4T-1
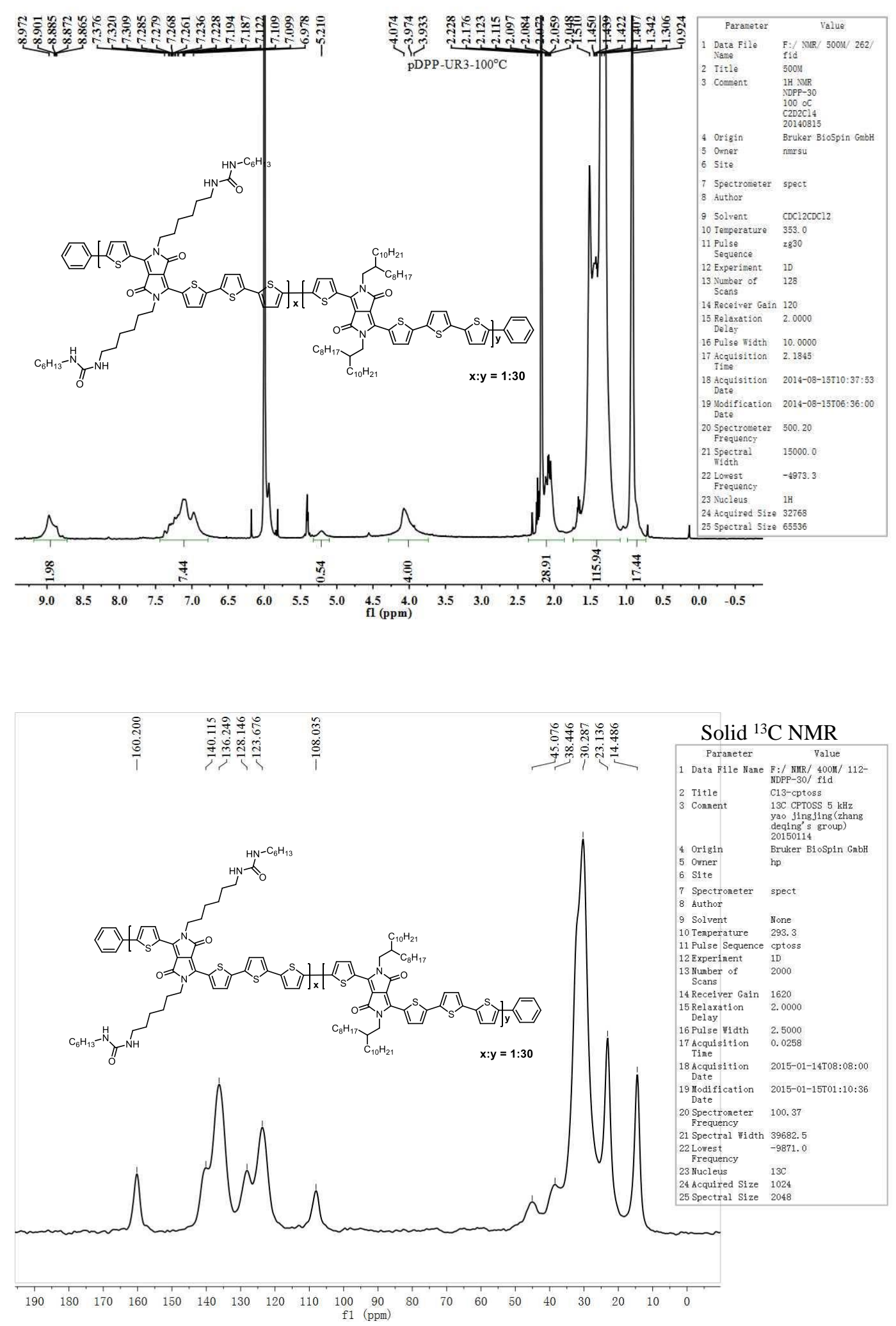


\section{pDPP4T-2}

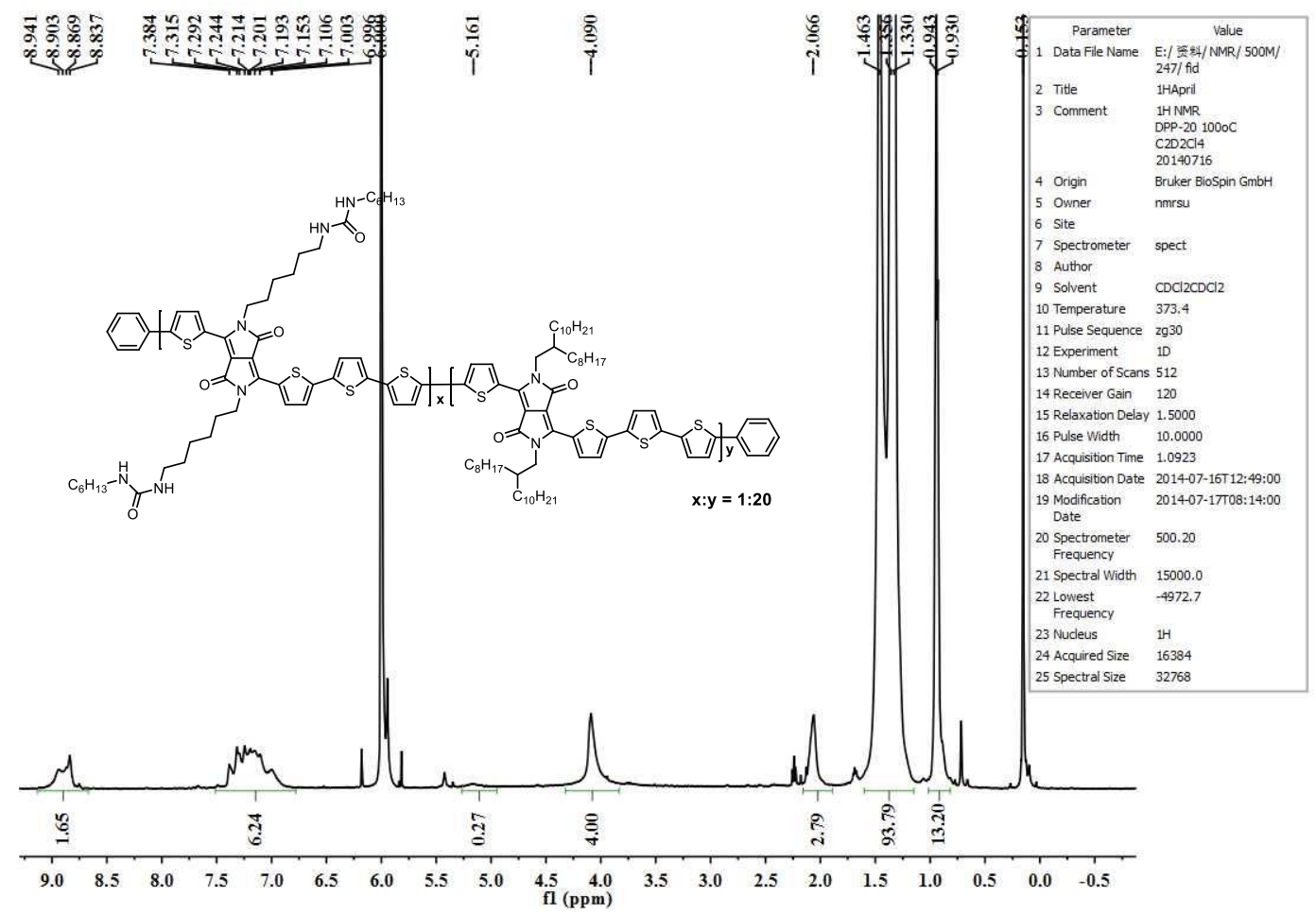

Solid ${ }^{13} \mathrm{C}$ NMR

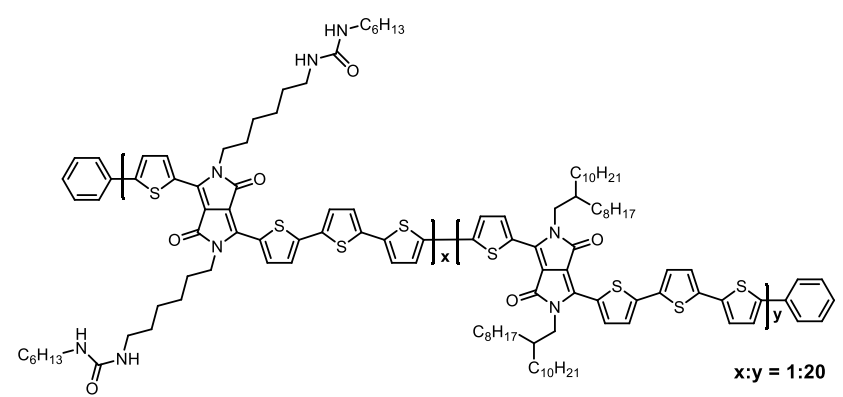

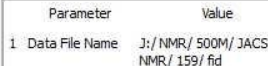
2. Thte N C13-pposs

3 Comment 13 CPTOSS 5 kHz 1\%
you jingjing (zhang

20150304

4 Origin Bruker Biospin Gmbr

5 Ouner hp

7 spectrometer spect

7 Spectrometer spect
8 Author

9. Solvent None

10 Temperature 294.4

$\begin{array}{ll}11 \text { Pulse Sequence cotoss } \\ 12 \text { Experiment } & 10\end{array}$

12 Experiment 10

13 Number of Scans 5140
14 Receiver Gain 1520

14 Receiver Gain 1620

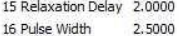

$\begin{array}{ll}16 \text { Pulse Width } & 2.5000 \\ 17 \text { Accuisition Time } & 0.0259\end{array}$

17 Acquistion Time 0.0258

18 Acquistion Date 2015-03-0400:11:00

19 Modification Date 2015-03-05103:02:26

20 Spectrometer 100.37

Freauency

21 Spectral Width 39682.5

N

N

N

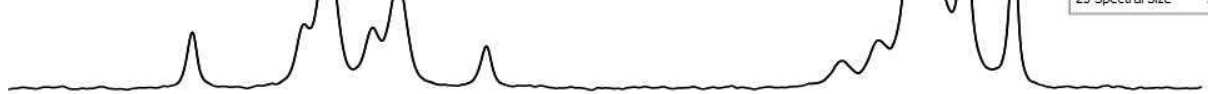

$\begin{array}{lllllllllllllllllllll}190 & 180 & 170 & 160 & 150 & 140 & 130 & 120 & 110 & 100 & 90 & 80 & 70 & 60 & 50 & 40 & 30 & 20 & 10 & 0 & -10\end{array}$ 
pDPP4T-3



\section{pDPP4T}



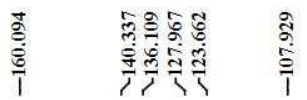

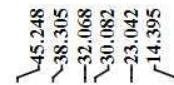

Solid ${ }^{13} \mathrm{C}$ NMR

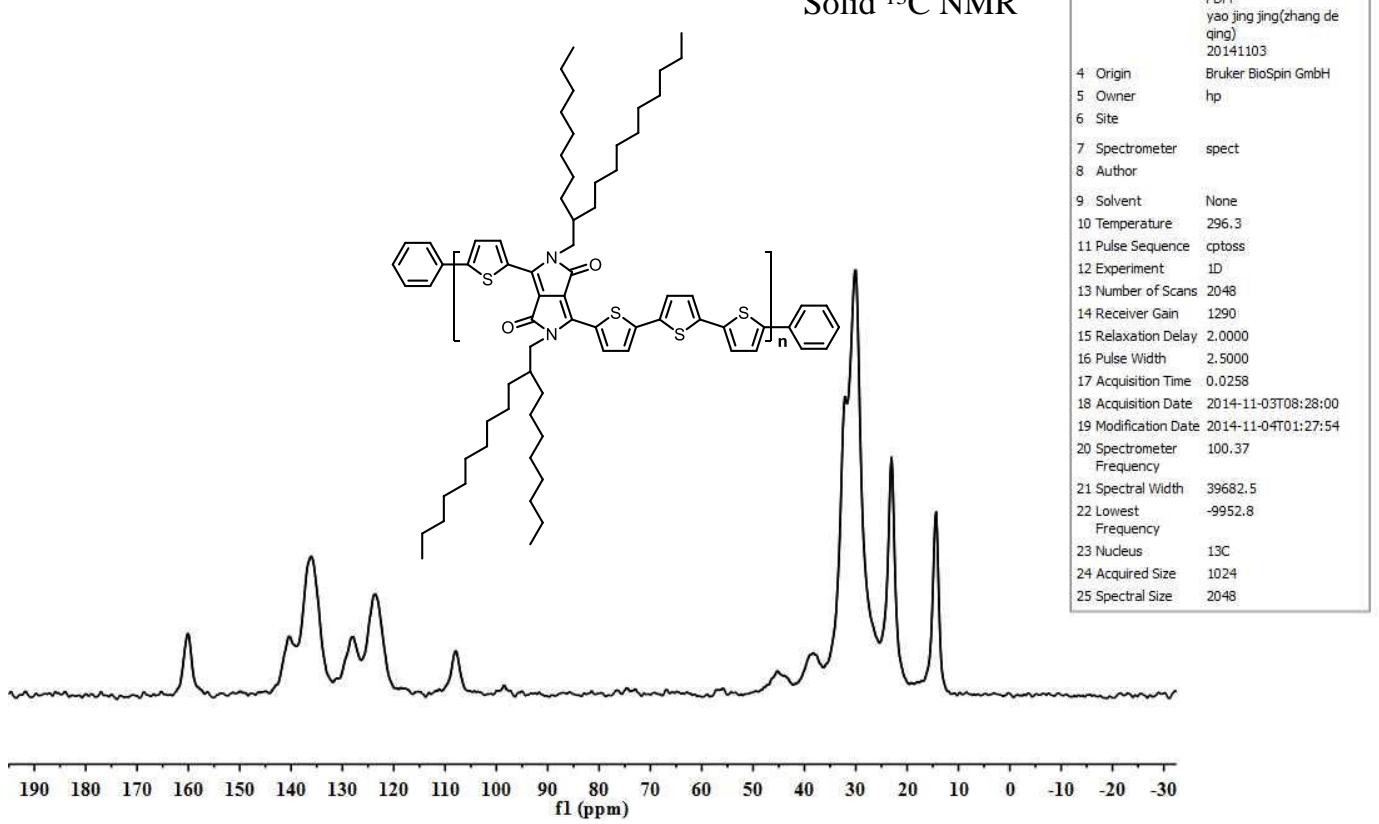


pDPP4T-A



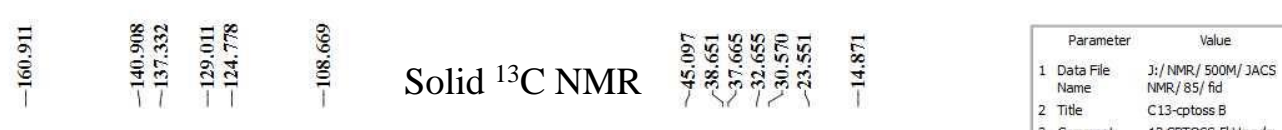

3 Comment 13 CPTOSS $5 \mathrm{KHz}$ ada yao jingjing (zhang deqing's group) 20151026
Origin $\quad$ Bruker BioSpin GmbH 6 site

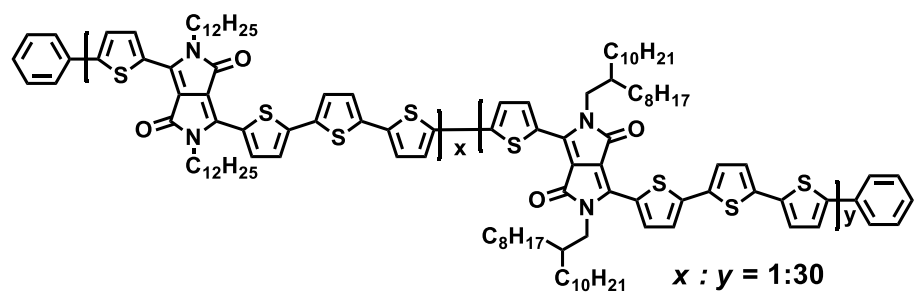

7 Spectrometer spect

7 Spectrometer spe
8 Author

9 Solvent None

10 Temperature 296.5

11 Pulse cptoss
Sequence

12 Experiment 10

13 Number of 1024

14 Receiver Gain 1030

$\begin{array}{ll}14 & \text { Receiver Gain } 1030 \\ 5 \text { Relaxation } \quad 2,0000\end{array}$

Delay
2.0000

16 Pulse Width 2.5000

17 Acquisition $\quad 0.0258$

8 Acquisition 2015-10-26T 10:52:00

19 Modification 2015-10-27101:13:20

20 Spectrometer 100.37

Spectrometer 100.37
Frequency

21 Spectral 39682.5

21 Spectral
Width
22 lowest

22 Lowest
Frequency

23 Nudeus $13 \mathrm{C}$

25 Spectral Size 2048

$\begin{array}{lllllllllllllllllll}170 & 160 & 150 & 140 & 130 & 120 & 110 & 100 & 90 & 80 & 70 & 60 & 50 & 40 & 30 & 20 & 10 & 0 & -10\end{array}$ 


\section{pDPP4T-B}

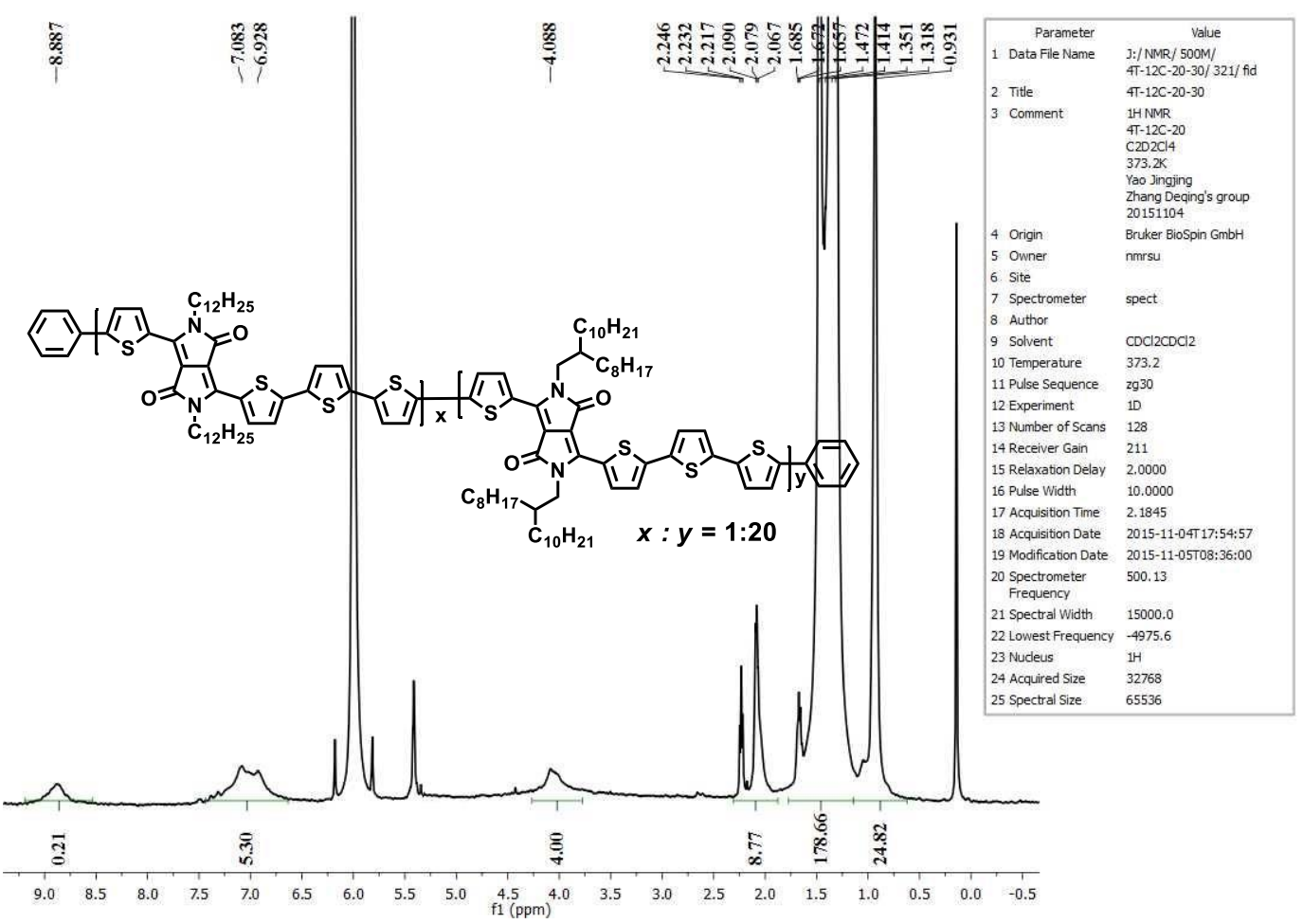

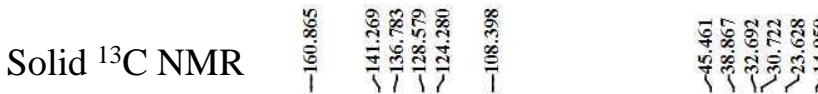

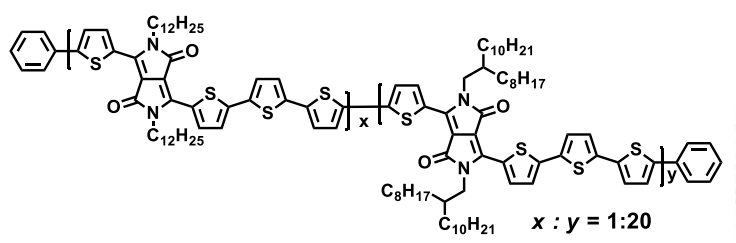

\begin{tabular}{ll}
$\quad$ Parameter & \multicolumn{1}{c}{ Value } \\
1. Data File & J:/ NMR/500M/JACS \\
Name & NMR/86/fid \\
2 Title & C13-cptoss B \\
& Cos
\end{tabular}

7 Spectrometer spect.

3 Author

9 Solvent None

10 Temperature 296.4

11 Pulse cptoss
Sequence

12 Experiment $1 D$

13 Number of 1024

Scans

14 Receiver Gain 1030

Relax
Delation 2.0000

16 Pulse Width 2.5000

17 Acquisition $\quad 0.0258$

18 Acquisition $\quad 2015-10-26 T 11: 31: 00$
Date

19 Modification 2015-10-27101:59:10

20 Spectrometer 100.37

20 Spectrometer 100.37
Frequency

21 Spectral 39682.5

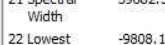

22 Lowest
Frequency

$\underbrace{23}_{24}$ Acquired Size 1024

25 Spectral Size 2048








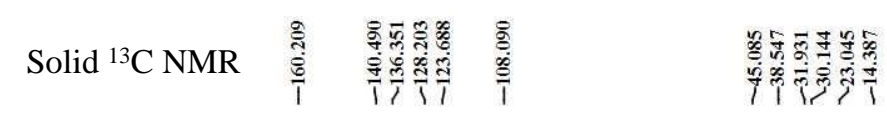
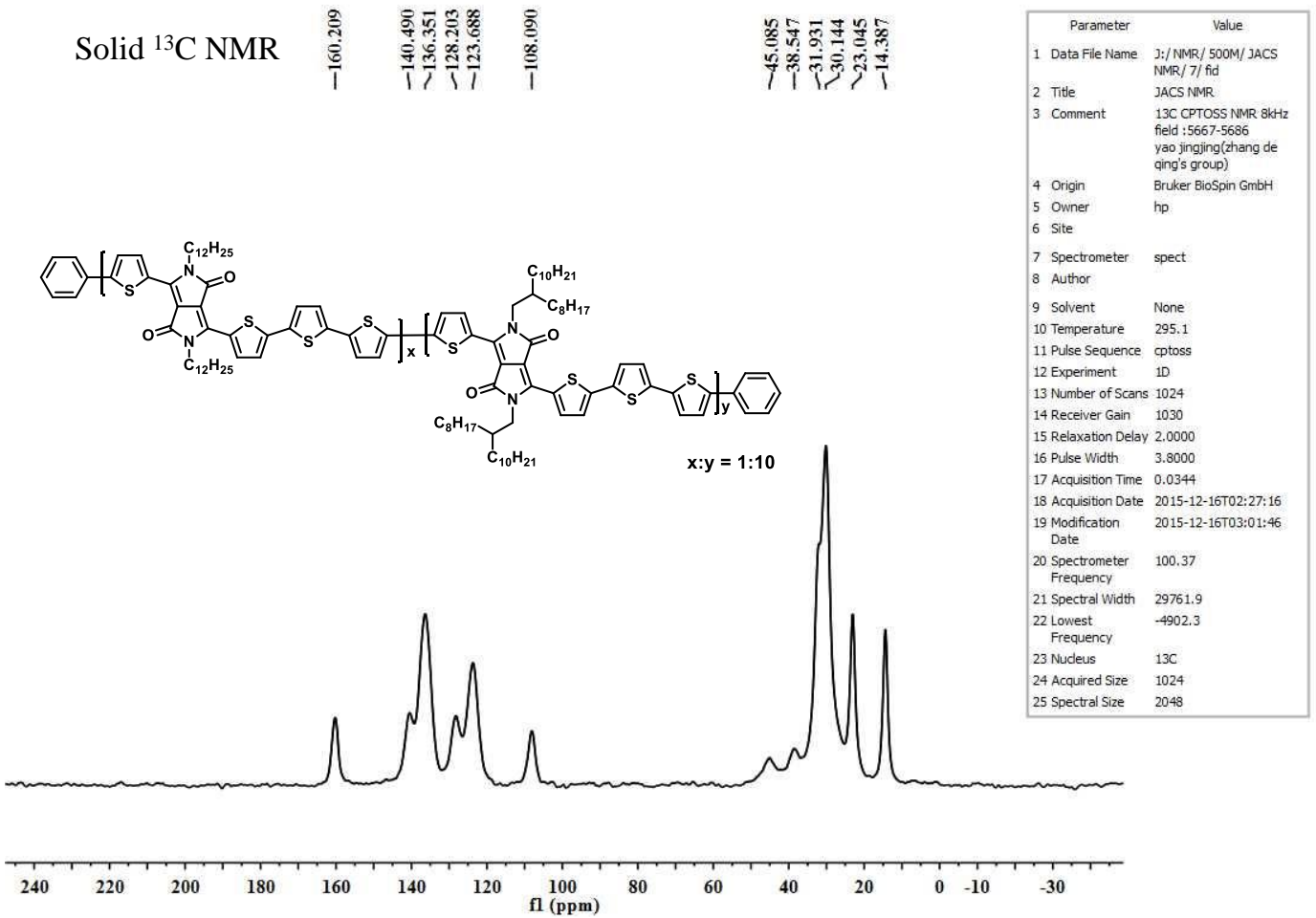